\title{
Estimation of Above Ground Biomass in Horton Plains National Park, Sri Lanka Using Optical, Thermal and RADAR Remote Sensing Data
}

\author{
A.R. Gunawardena*, S.P. Nissanka ${ }^{1}$, N.D.K. Dayawansa ${ }^{2}$ and T.T. Fernando ${ }^{3}$ \\ Postgraduate Institute of Agriculture ${ }^{1}$ \\ University of Peradeniya \\ Sri Lanka
}

\begin{abstract}
A variety of approaches have been developed to estimate the aboveground biomass. However, methods differ in procedure, complexity and time requirement depending on the specific aim of these estimations. Remote Sensing (RS) is popular as a nondestructive method of biomass estimation since it can reduce the measurements and monitoring in the field to a considerable extent. This study focused to estimate above ground biomass of Horton Plains national park of Sri Lanka using ALOS PALSAR, IRS LISS III and Thermal bands of Landsat OLI images. There were 55 field sampling plots used and diameter at breast height, total tree height, and canopy cover percentage of all trees $(\mathrm{dbh}>10 \mathrm{~cm})$, and slope and GPS locations of each sampling plots were collected. Previously developed relevant allometric equations were used to estimate biomass using DBH and height in each plot. The relationship between backscatter coefficient of the ALOS PALSAR image, Normalized Difference Vegetation Index derived from IRS LISS III image and surface temperature generated form Landsat OLI thermal images were correlated with field estimated biomass to observe there correlation. It was not possible to obtain very strong correlations between these variables and AGB. However, a positive linear correlation between AGB and NDVI was relatively high compared to other vegetation indices. The amount of biomass calculated for three different correlations obtained for NDVI, Backscatter HH, Backscatter HV and land surface temperature are $41.76 \mathrm{t} / \mathrm{ha}, 38.9 \mathrm{t} / \mathrm{ha}$, 32.5 t/ha and 62.72 t/ha respectively.
\end{abstract}

Keywords: Above ground biomass, remote sensing, forest, satellite images, carbon sequestration

\section{INTRODUCTION}

Terrestrial carbon sequestration in above ground woody biomass has received attention as an immediate attempt to mitigate global warming. Biomass estimates provide a means of calculating the amount of carbon dioxide that could be removed/fixed from the atmosphere by re-growing vegetation. Many attempts have been made to estimate vegetation biomass and use of existing forest inventory can be identified as a key method. Researchers have developed various methods for the quantification of sequestered carbon (Brown et al., 1989).

\footnotetext{
1 Department of Crop Science, Faculty of Agriculture, University of Peradeniya, Sri Lanka

2 Department of Agricultural Engineering, Faculty of Agriculture, University of Peradeniya, Sri Lanka

3 Central Environmental Authority, Sri Lanka

* Corresponding author: ajiththeja@gmail.com
} 
Traditional inventory of forest parameters based on fieldwork is often difficult, costly and time consuming to conduct in large areas. Furthermore, complexity of forest structure and inaccessible nature of many tropical forests limits the feasibility of ground based inventory. Remote sensing is one of the feasible ways to acquire forest stand parameter information at a reasonable cost with an acceptable accuracy. Advanced new remote sensing techniques such as multi-sensor data fusion, increased spatial and spectral resolution and integration possibility with Geographical Information Systems (GIS) have made the remotely sensed data a primary source for many forestry applications. Among them, extraction of forest stands parameters through correlation or regression analysis to examine relationship between spectral response and structural factors of forest such as basal area, biomass, crown closer and vegetation density estimations (Namayanga, 2002) can be identified as very important. Observation and measurements by satellite based remote sensing have currently become one of the key sources of information in estimating AGB in tropical forest (Lu, 2006). A number of studies have evaluated remote sensing techniques for mapping of forests and forest stand parameters, including height, age, density, biomass and leaf area index, using optical remote sensing (Boyd et al., 1999; Foody et al., 2001, Foody, 2003; Lu, 2005; Steininger, 2000; Thenkabail et al., 2004). Vegetation indices are the most widely used approach (Foody, 2003). Most indices depend on the relationship between red and near-infrared wavelengths to enhance the spectral contribution from green vegetation while minimizing contributions from the soil background, sun angle, sensor view angle, vegetation and the atmosphere (Huete et al., 1985; Tucker, 1979). However, vegetation indices have achieved only moderate success in tropical and subtropical regions where biomass levels are high, the forest canopy is closed, with multiple layering, and greater species diversity (Foody et al., 2001; Lu, 2005; Nelson et al., 2000).

Difficulty to acquire cloud free images in tropical region is one of the key challenges in using optical remote sensing data under Sri Lankan condition. Space borne synthetic aperture radar (SAR) sensors such as the L-band ALOS PALSAR, the C-band ERS/SAR, RADARSAT/SAR or ENVISAT/ ASAR and the X-band Terra SAR-X instrument are active systems, transmitting microwave energy at wavelengths from 3.0 (X-band) to $23.6 \mathrm{~cm}$ (Lband). The major advantage of SAR systems is their weather and daylight independency. In addition, the ability to penetrate into the volume of the object (canopies) which depend on the wavelength is another important character. The degree of penetration depends on the wavelength so the sensor's ability to estimate biomass. The ability to measure biomass is additionally affected by the polarization and the incidence angle of the sensor, and land cover and terrain properties (Lu, 2005).

\section{Objectives}

This study attempts to estimate the above ground biomass in Horton Plains National Park (HPNP) using a vegetation index derived from IRS LISS III (2008) optical and Infra-red data; thermal infrared band of Landsat OLI (2013) and backscatter coefficient of ALOS PASLAR (HH, HV) (2010) images.

\section{METHODOLOGY}

\section{Study area and sampling sites}

Horton Plains National Park (HPNP) is situated $2200 \mathrm{~m}$ above mean sea level in the Nuwara Eliya District of the Central Province of Sri Lanka. The geographical location of the Horton 
Plains is shown in Fig. 1. This study included the Thotupala mountain area also and the total area accounting to 3162 ha. The Climate of Horton Plains is almost similar to a wet Montane forest. Undisturbed old-growth forest is low in stature $(15-20 \mathrm{~m})$ and canopy trees are characteristically gnarled and twisted, bonsai, due to the lower temperatures and high winds. The canopy is dominated by species such as Calophyllum walkeri, Michelia nilagirica, Syzygium rotundifolium, S. revolutum, Elaeocarpus montanus, E. glandulifer, E. coriaceous, Ilex walkeri, Cinnamomum ovalifolium, Litsea ovalifolia and Photinia integrifolia. The forest understory is somewhat darker but easy to access due to the low density of seedlings, saplings and herbaceous plants. Many bryophytes, epiphytes (orchids, lichens, bryophytes and ferns) and filmy ferns grow on the stems and branches of trees (DWC, 2007).

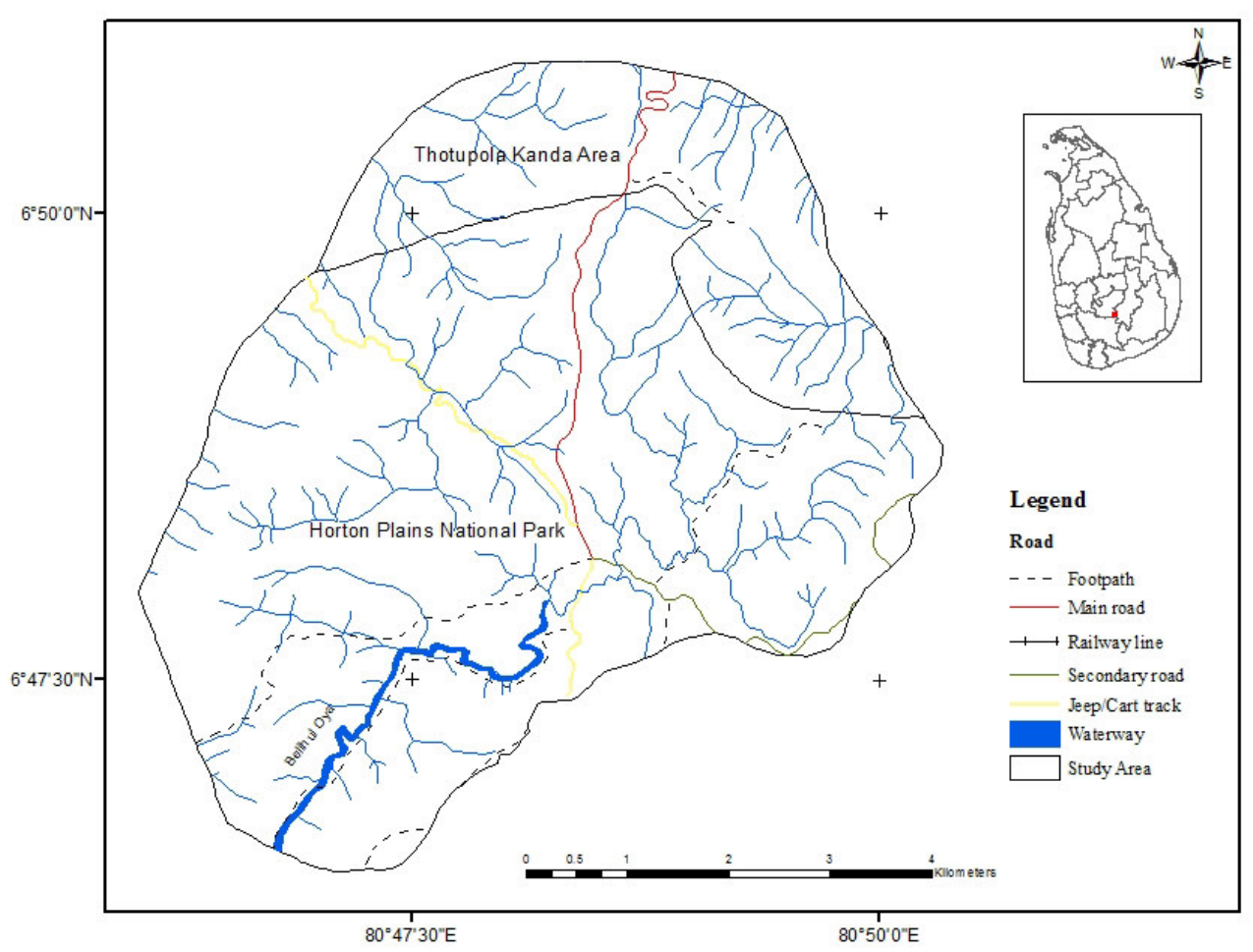

Fig. 1. Location map of the Horton Plains National Park

\section{Data, materials and other information}

The primary data used in the study was Landsat OLI (30 ${ }^{\text {th }}$ August 2013), IRS LISS III (2008) and ALOS PALSR (HH, HV) dual polarization image (21 $1^{\text {st }}$ June 2010), and Google Earth images were used for visual interpretation. Demarcation and identification of sampling sites were carried out using 1:10,000 topographic maps of the Survey Department of Sri Lanka and differential GPS receiver was used to identify the geographical locations. Acquired images were originally geo-referenced to UTM (Universal Transverse Mercator) projection with the datum of WGS 84 (zone 44N). 


\section{Optical image classification}

Remote sensing image classification can be viewed as a joint venture of both image processing and classification techniques. Generally, the image classification in the field of remote sensing is the process of assigning pixels or the basic units of an image to classes. It is likely to assemble groups of identical pixels found in remotely sensed data into classes that match the information categories of user interest by comparing pixels to one another and to those of known identity (Lu, 2006). Supervised and unsupervised classification techniques were used to extract ground cover information from satellite images in the study area.

\section{Development of Vegetation Indices with Optical and Near Infrared Images}

Vegetation Indices (VIs) are combinations of surface reflectance at two or more wavelengths designed to highlight a particular property of vegetation. They are derived using the reflectance properties of vegetation. Each of the VIs is designed to accentuate a particular vegetation property. More than 150 VIs have been published in scientific literature, but only a small subset has the substantial biophysical basis or has been systematically tested (http://www.exelisvis.com/). Among them, Normalize Difference Vegetation Index (NDVI), Ratio Vegetation Indices, Transformed VI, and Soil Adjusted vegetation index are widely used for estimation of biophysical parameters of the natural vegetation (Densheng et al., 2004). NDVI is the widely used vegetation index than other VI's for estimation of biomass (Panda, 2005) and this study also used NDVI calculated from IRS LISS III imagery.

\section{Normalize Difference Vegetation Index (NDVI)}

NDVI formula provides a combination of red and near infrared spectral reflectance from the vegetation canopy as shown in Equation 1

$$
\mathrm{NDVI}=(\mathrm{NIR}-\mathrm{Red}) /(\mathrm{NIR}+\mathrm{Red}) \quad(\text { Equation } 1)
$$

\section{Developing Land Surface Temperature using Thermal Infrared band of Landsat 8 OLI}

Land surface temperature (LST) is related to surface energy and water balance, at local through global scales, with principal significance for a wide variety of applications, such as climate change, urban climate, the hydrological cycle, and vegetation monitoring (Wan et al., 2004). Landsat- 8 was launched on 11 February 2013 and deployed into orbit with two instruments on-board: (1) the Operational Land Imager (OLI) with nine spectral bands in the visual (VIS), near infrared (NIR), and the shortwave infrared (SWIR) spectral regions; and (2) the Thermal Infrared Sensor (TIRS) with two spectral bands in the LWIR. The spatial resolution of TIRS data is $100 \mathrm{~m}$ (resampled into $30 \mathrm{~m}$ ) with a revisit time of 16 days (Rozenstein et al., 2014). In this study, TIRS bands were used to develop the land surface temperature map to find the relationship between AGB and surface temperature (Rozenstein et el., 2014).

\section{Calculation of backscattering coefficient using ALOS PALSAR image}

Cloud-free synthetic aperture radar (SAR) has the potential to be an important data source for tropical forest mapping and there is no reported use of PALSAR data to generate biomass in Sri Lankan vegetation yet. Previous studies have shown that longer radar wavelengths (e.g. L-band SAR) are more suitable for the delineation of forest than shorter wavelengths 
because of their greater penetration through the tree canopy (Baghdadi et al., 2009). The Phased Array Type L-band Synthetic Aperture Radar (PALSAR) onboard the Advanced Land Observing Satellite (ALOS) was launched by the Japan Aerospace Exploration Agency (JAXA) in January of 2006 and provides polarimetric radar images of the global land surface that have been used for forest mapping (Almeida et al., 2009).

ALOS -PALSAR images with HH polarization and HV polarization were used to calculate the backscattering coefficient. The DN (Digital Number) of the HH and HV polarized images were converted into backscattering coefficient values using Equation 2 (Shimada et al., 2009).

$$
\begin{aligned}
& \sigma^{\circ}=10 * \log 10\left(\mathrm{DN}^{2}\right)-83 . \\
& \sigma^{\circ}=\text { Backscattering Coefficient }
\end{aligned}
$$

The methodology of biomass estimation are summarized in the Fig. 2.

\section{Field data collection}

Ground survey was carried out to collect information on forest stand parameters of Horton Plains from 55 selected locations (plot size 30x30 m). Canopy cover percentage, ground cover percentage, Diameter of Breast Height $(\mathrm{DBH})$, total tree height and ground opening areas were measured. Field data collection was done during 2011-2013 period.

\section{Estimation of biomass through field sampling}

There are many regression models available for the estimation of AGB developed by many scientists considering stem diameter, wood density and tree height ((Zanne et al., 2009); Chave et al. (2005); Bao Huy et al. (2012) and Brown and Lugo (1982)). The evaluation of above-ground carbon of woody plants was concentrated only to tree species which are having DBH of $\geq 10 \mathrm{~cm}$, excluding lianas, and non-woody monocots. The following allometric regression model (Brown et al., 1989) (Equation 3) was applied for individual plants to convert the inventory data into the above ground biomass for 27 tree dominated plots. The allometric regression models were selected based on published literature considering their suitability to be used for tropical forests and biogeographic zone of the present investigation.

$$
\begin{aligned}
& \mathrm{AGB}=13.2579-4.8945(\mathrm{DBH})+0.6713(\mathrm{DBH})^{2}-\quad(\text { Equation 3) (Brown, 1989) } \\
& \mathrm{AGB}=\text { above-ground tree biomass }(\mathrm{t}) \mathrm{DBH}=\text { tree diameter at breast height }
\end{aligned}
$$

The selected allometric model is only applicable to estimate AGB in tree dominated plots in natural forests. Therefore, low dense vegetation (scrubland and grasslands having $<10 \mathrm{~cm}$ $\mathrm{DBH})$ areas AGB were estimated through the previously derived relationships as given in Equations $4 \& 5$.

$$
\begin{array}{ll}
\begin{array}{l}
\text { Grasslands } \quad \mathrm{y}=-61+16300(\mathrm{NDVI}) \\
\text { Y= above ground live biomass }(\mathrm{kg})
\end{array} & \begin{array}{l}
\text { (Equation 4) } \\
\text { (Foster } \text { et al., 2012) }
\end{array} \\
\text { Scrublands } \quad \mathrm{y}=9.17+3.00 \mathrm{Ln}(\mathrm{NDVI}) & \text { (Equation 5) }
\end{array}
$$


$\mathrm{Y}=$ above ground live biomass $(\mathrm{t})$

(Aranha et al., 2008)

\section{Correlations between estimated biomass and NDVI, Land Surface Temperature (LST) and backscattering coefficient derived from satellite data}

The dense and moderately dense vegetation areas identified through image classification were subjected to estimation of biomass using standard allometric equations. It was attempted to correlate these estimated biomass with the NDVI derived using IRS LISS III, land surface temperature derived from Landsat $8 \mathrm{OLI}$, and backscattering coefficient $\mathrm{HH}$, HV Polarization) derived from ALOS PALSAR data using Pearson's correlation coefficient.

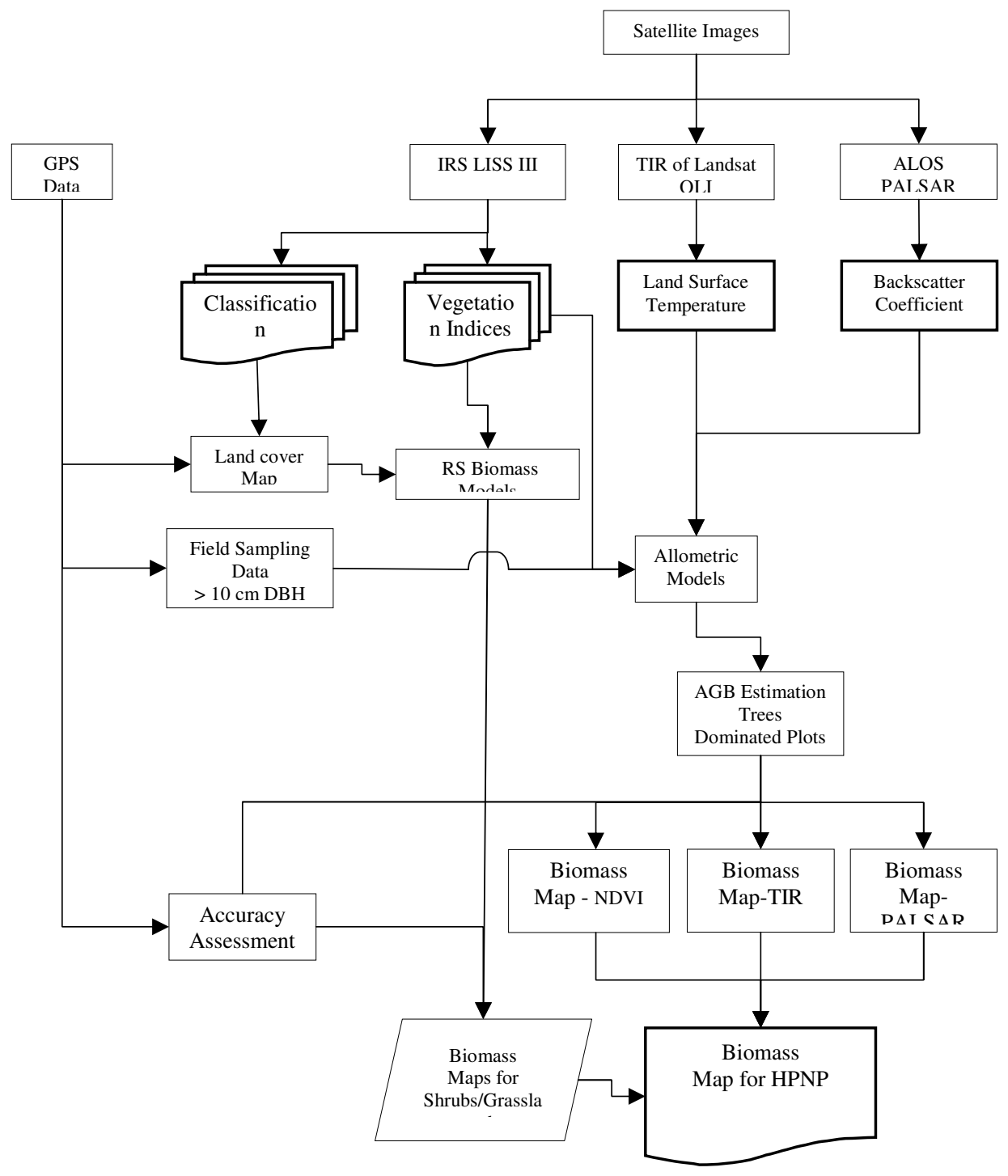

Fig. 2. Flow diagram of the methodology 


\section{RESULTS AND DISCUSSION}

\section{Development of land cover map of HPNP}

Initially, 12 land cover classes were derived using unsupervised classification of IRS LISS III (2008) satellite image and were further generalized to 4 classes with the aid of groundtruth data and visual interpretation of Google Earth high resolution satellite images. Accordingly, four classes were identified as dense forest ( $850 \mathrm{ha})$, moderately dense vegetation (1,957 ha), low dense vegetation (554 ha) and grasslands (655 ha) (Fig. 3). The dense vegetation is widely distributed in western and north western regions while grasslands are located in the middle part of the plain. Field sampling plots were placed using representative sampling technique in each land cover type. The overall accuracy of land cover map reached $78 \%$ and the highest accuracy was achieved in dense forest and grasslands.

\section{Biomass estimation through field sampling}

Out of the total plots (55), 27 plots came under dense and moderately dense vegetation $(>10 \mathrm{~cm} \mathrm{DBH})$ which were used to estimate AGB through an allometric equation (Brown, 1989). The highest estimated AGB was observed as $81.68 \mathrm{t} / \mathrm{ha}$ in plot number 53 while lowest was observed in Plot 23 (4.599 t/ ha) due to the variation of number of trees, DBH, and height variations. The mean AGB was calculated as 50.17 t/ha in HPNP. The AGB estimations made by Eskil et al. (2012) by forest inventory data has observed AGB as 43 50 t/ha. A similar study conducted by Forest Carbon Asia Country Profile has estimated the same as $14.2 \mathrm{t} / \mathrm{ha}$ (Fig. 4) for montane forest regions of Sri Lanka (Chokkalingam \& Vanniarachchy, 2011).

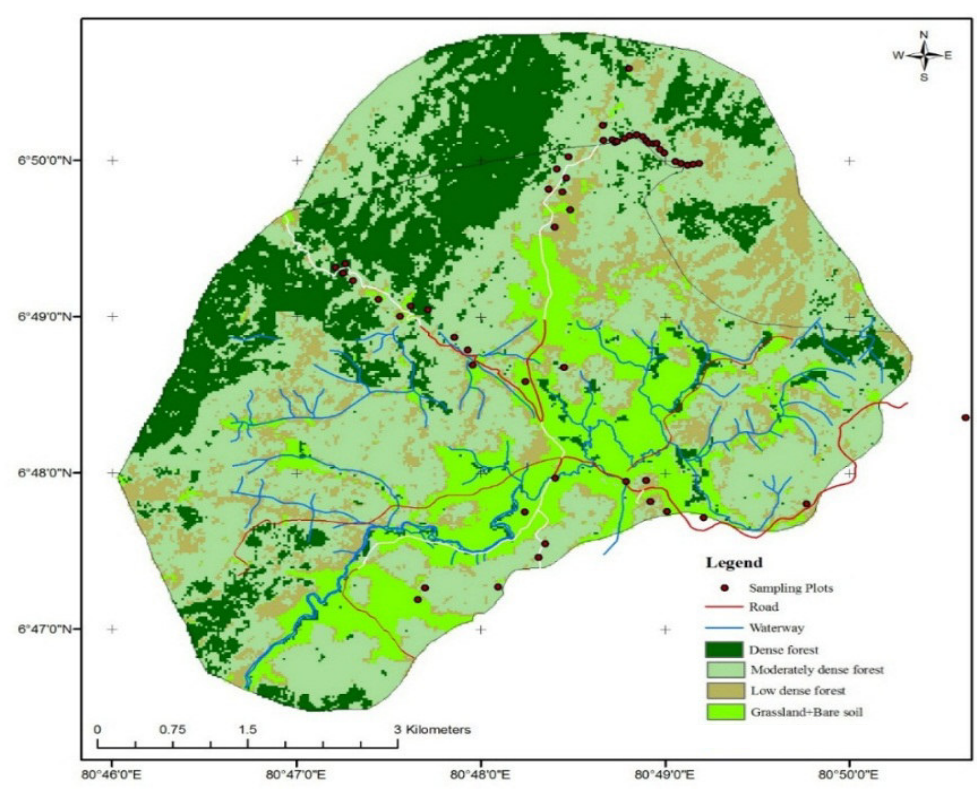

Fig 3. Land cover map of HPNP and surrounding area developed using unsupervised classification of IRS LISS III image 


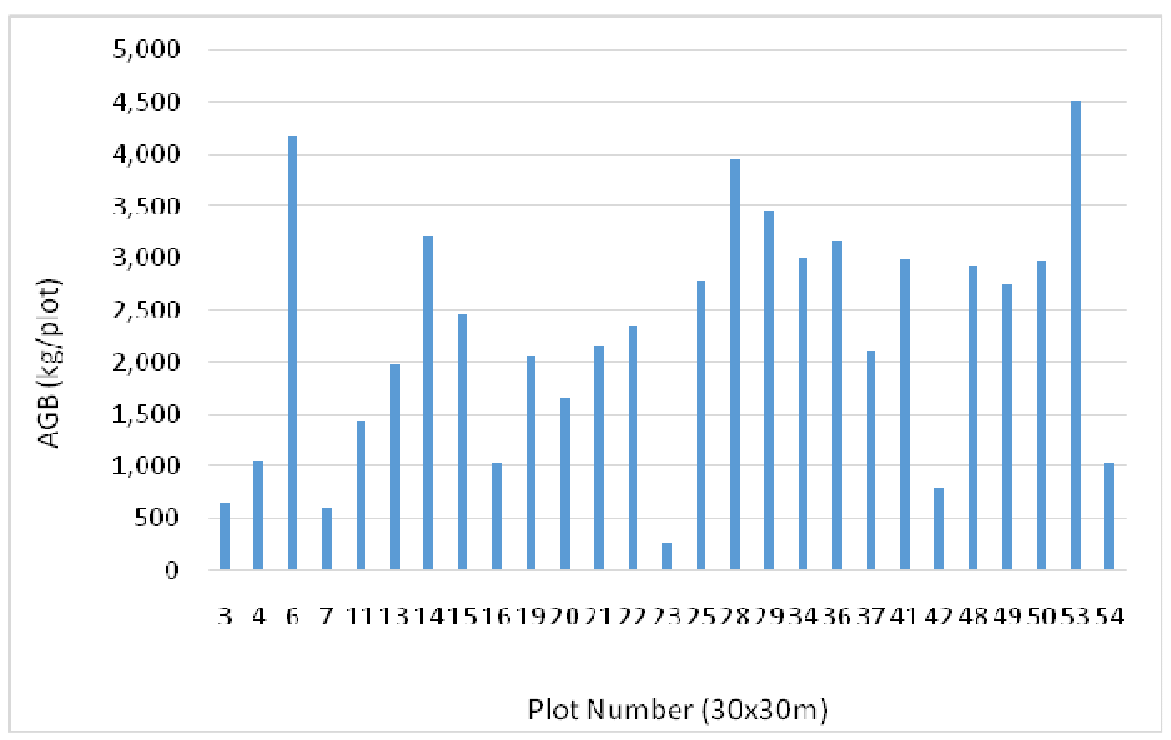

Fig. 4. Estimated AGB through field sampling data in tree dominated plots

\section{Relationship between estimated biomass with NDVI from IRS LISS III image}

The relationship between NDVI with estimated AGB is shown in Fig 6. The relationship derived using NDVI and estimated AGB is given in Equation 6.

$$
\mathrm{AGB}=10,077 * \mathrm{NDVI}-2,936.8 \quad \text { (Equation 6) }
$$

Using Equation 6, AGB maps were prepared for the tree dominated dense and moderately dense vegetation. However, derived equation cannot be applied for the grassland and scrub dominated vegetation due to extreme over estimation of AGB.

Table. 1. Correlations between estimated biomass with vegetation indices, Land surface temperature and backscattering coefficient derived from satellite data

\begin{tabular}{lcrrr}
\hline & NDVI & HH & \multicolumn{1}{c}{ HV } & \multicolumn{1}{c}{ LS T } \\
\hline Pearson's Correlation & 0.712 & 0.587 & 0.441 & -0.594 \\
Sig. (2-tailed) & 0.000 & 0.001 & 0.021 & 0.001 \\
N (No of plots) & 27 & 27 & 27 & 27 \\
\hline
\end{tabular}

Accordingly, the AGB in tree dominated areas were calculated as $41.76 \mathrm{t} / \mathrm{ha}$ which gave $17 \%$ underestimation comparative to the field estimated biomass. Fig. 7 presents the AGB distribution in dense and moderately dense vegetation areas in Horton Plains. Some satellite driven models have been developed by many scientists to estimate above ground biomass for different vegetation types. Roy \& Shirish (1996) used Landsat TM derived NDVI and Middle Infrared (MIR) Ratio to predict biomass content of natural forests in India and obtained 90\% accuracy. Lue et al. (2003) found the relationship between multi-angular 
satellite remote sensing (AVHRR and MODIS) and forest inventory data for carbon stock and sink capacity estimation. Similar study has been carried out to establish a relationship between forest stand parameters and Landsat TM spectral response in the Brazilian Amazon forest (Dengsheng et al., 2004) and found that tree height is strongly affected to the correlation between biomass and basal area distribution. In this study, for scrublands which were having DBH less than $10 \mathrm{~cm}$ and for the grasslands, AGB was estimated separately using direct use of NDVI without correlating with field sampling data (Foster et al., 2012 and Aranha et al., 2008). Though the accuracy of this method is much lower than the field sampling technique, this method can be considered as quick and low cost way of estimating AGB. Distribution of Grassland and Scrubland AGB in HPNP are mapped in Fig. 8 (a and b).

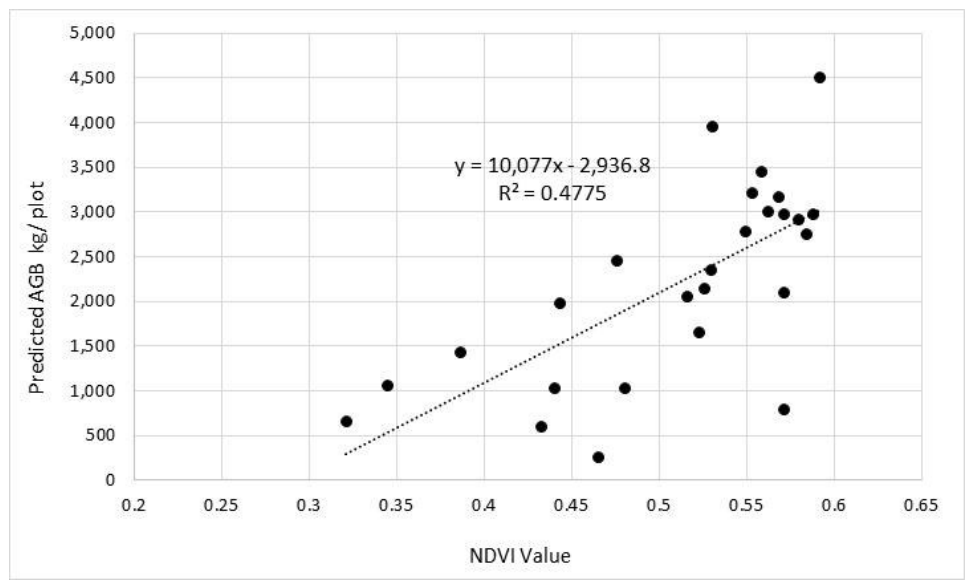

Fig. 6. Relationship between estimated AGB (trees dominated plots) with NDVI derived from IRS LISS III satellite image

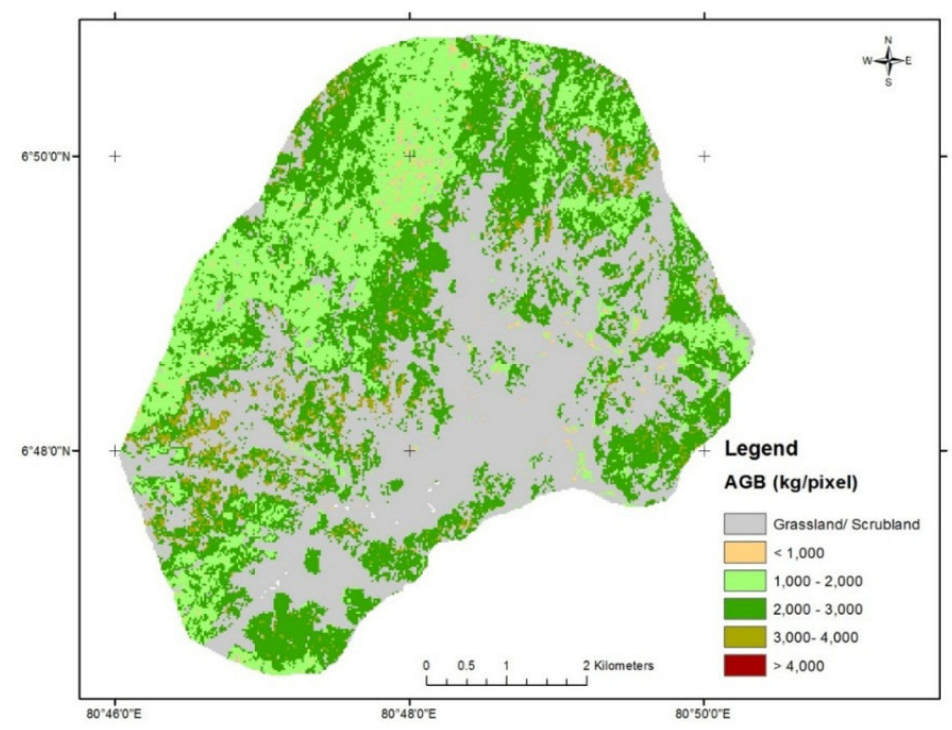

Fig. 7. Distribution of AGB with in dense and moderately dense vegetation in HPNP derived from NDVI of IRS LISS III data 

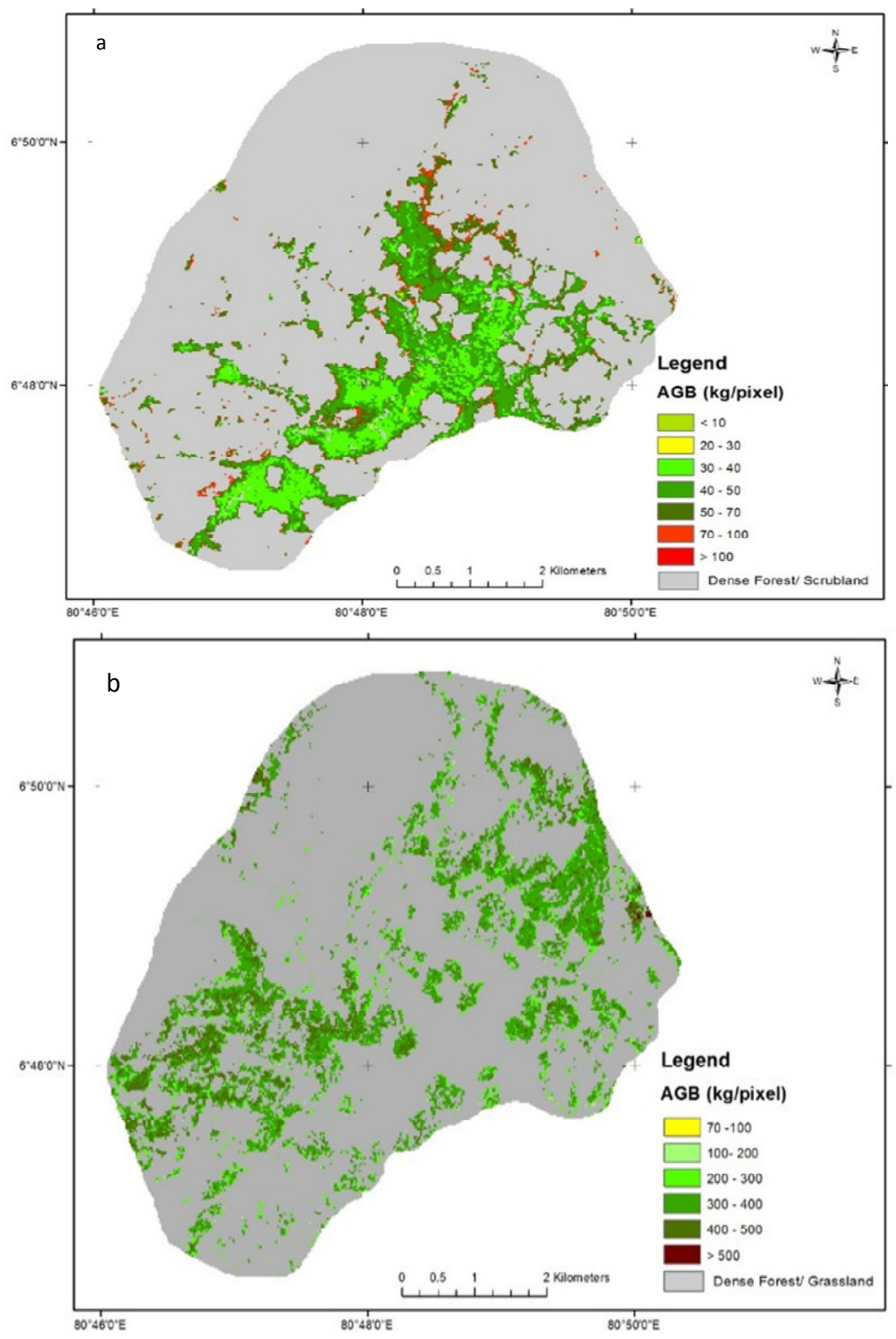

Fig. 8. Distribution of AGB within grassland (a) scrubland (b) dominated vegetation in HPNP derived from direct use of NDVI

\section{Relationship between estimated biomass with backscattering coefficient of ALOS PALSAR image}

Backscattering coefficient derived from ALOS PALSAR data were correlated with estimated AGB in tree dominated plots. A weak negative correlation was observed between the two variables (Fig. 9). According to the derived equations, the average AGB (dense and moderately dense vegetation) calculated form $\mathrm{HH}$ polarized image was $38.9 \mathrm{t} / \mathrm{ha}$ and from HV polarized image was $32.5 \mathrm{t} / \mathrm{ha}$. However, these values are not very reliable since the relationship between backscatter and AGB is weak. 


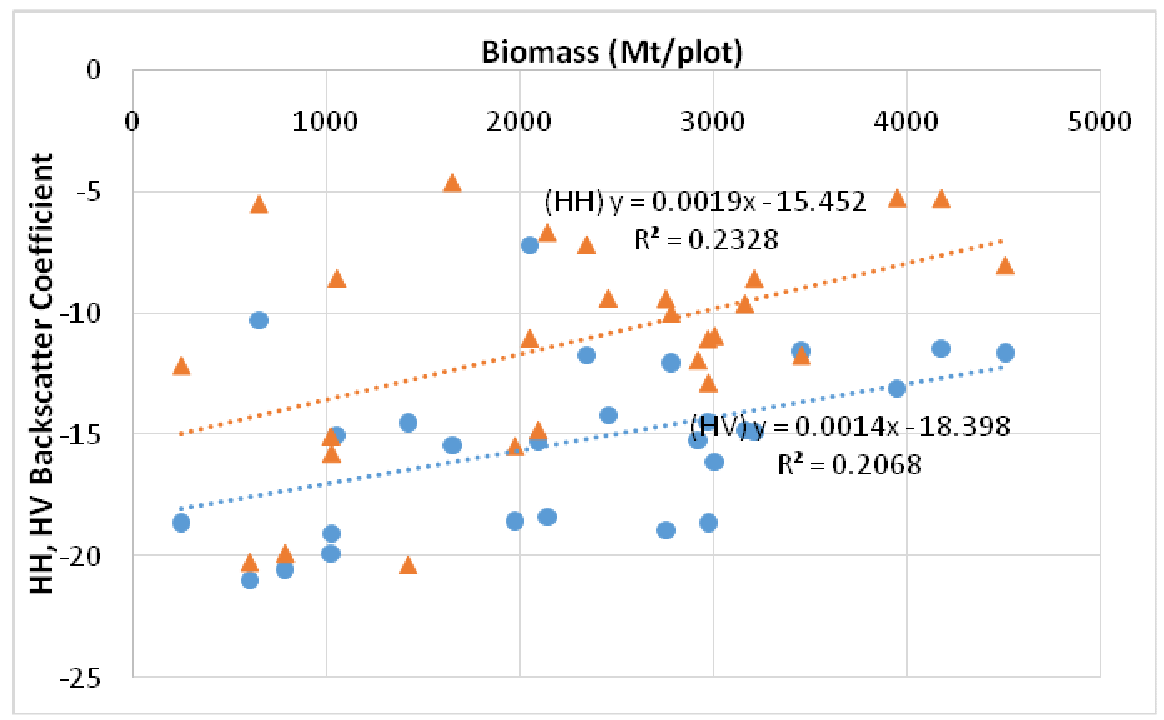

Fig. 9. Relationship between estimated AGB (trees dominated plots) with Backscattering coefficient derived from HH and HV polarized ALOS PALSAR images.

\section{Relationship between estimated biomass with land surface temperature derived from Landsat 8 TIRs band}

The derived land surface temperature values were correlated with the estimated biomass and vegetation types to investigate any possible relationship. Accordingly, a poor negative correlation was observed between the two variables with a $\mathrm{R}^{2}$ value of 0.35 (Fig. 10). The AGB calculation was carried out with the derived relationship (AGB $=-634.58$ LST $+14,502$ ) and is shown in Fig. 11. According to the relationship, it is evident that when the biomass content is high, the surface temperature of the vegetation areas are low indicating a good canopy cover. The average AGB of dense and moderately dense vegetation were estimated as $62.72 \mathrm{t} / \mathrm{ha}$ which is a $21 \%$ over estimation than the field estimated biomass. However, the development of the biomass estimation map was a challenging task due the variation of surface temperature at a rate of $\pm 6{ }^{\circ} \mathrm{C}$. The temperature distribution among the land cover classes is shown in Fig. 11. 


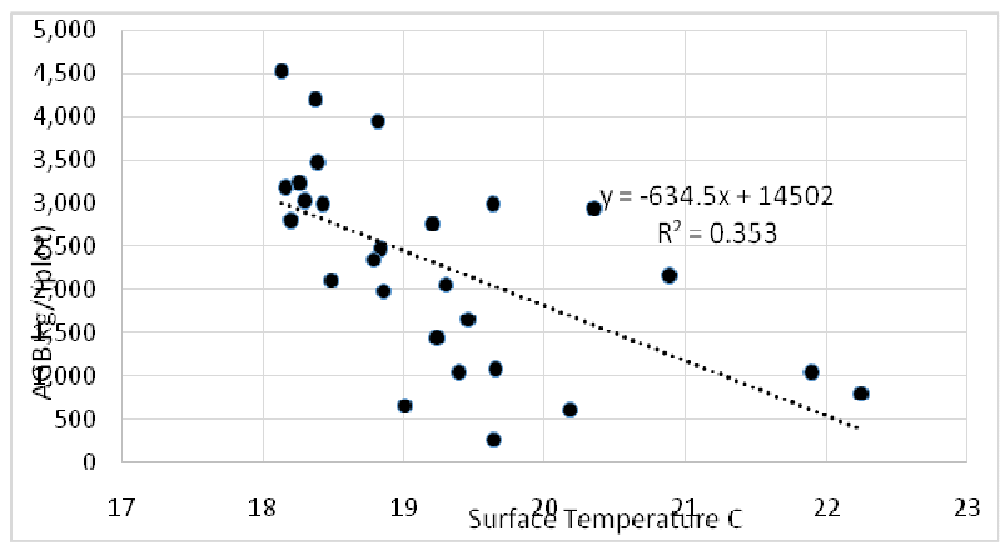

Fig. 10. Relationship between land surface temperature generated from Landsat TIR band 10 and estimated trees dominated plot biomass of HPNP.

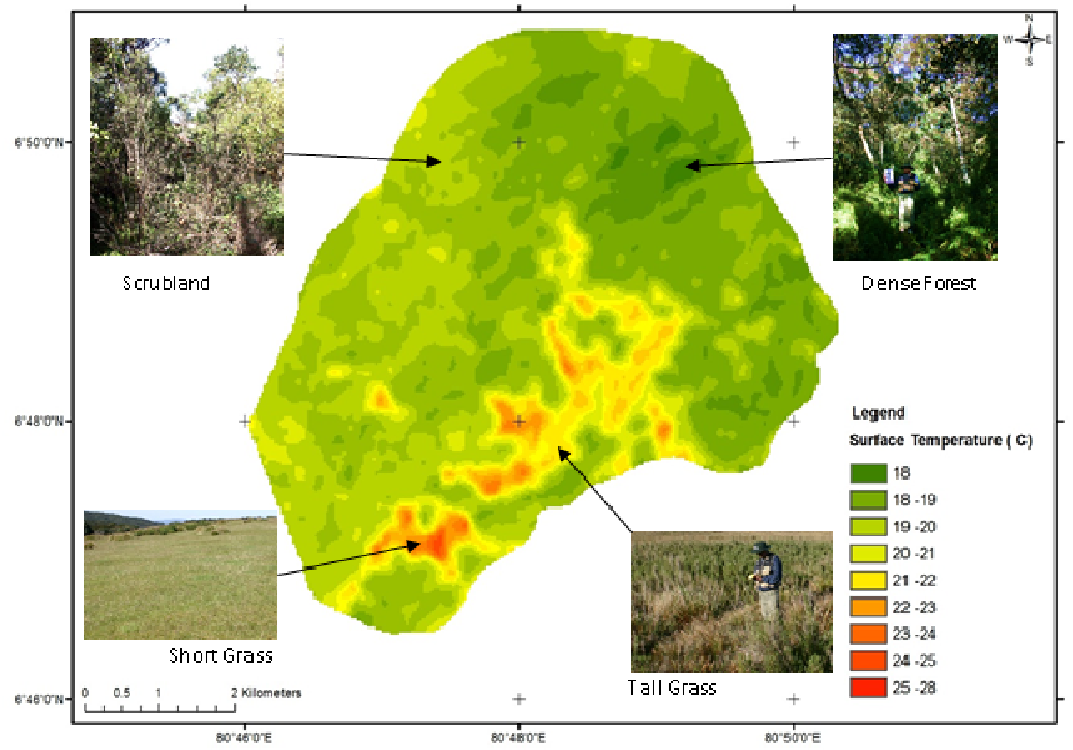

Fig. 11. Land surface temperature distribution in HPNP by Landsat TIR band 10

\section{Accuracy Assessment}

Accuracy assessment was done by obtaining field biomass estimations from another 8 post random sampled plots representing dense and moderately dense vegetation (Fig. 12). The overall accuracy of AGB estimation using NDVI was identified as $72.3 \%$. With backscattering coefficient of $\mathrm{HH}$ polarization, the accuracy was identified as $71 \%$ and with HV polarization it was $68 \%$ comparative to the field estimated biomass. 


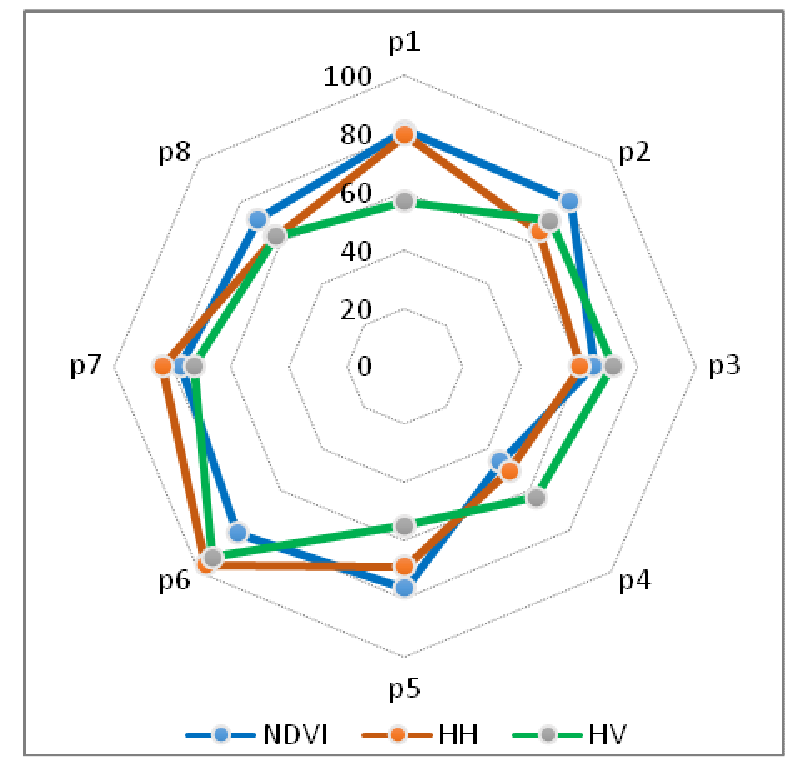

Fig. 12. Distribution of estimated AGB accuracy derived from NDVI, HH, and HV

\section{CONCLUSIONS}

Three remote sensing based parameters were used to explore a correlation between above ground biomass estimated in dense and moderately dense vegetation using field sampling techniques. The study identified that NDVI is the most suitable vegetation index to estimate AGB in dense and moderate dense vegetation areas. A positive linear correlation was observed between AGB and NDVI. Though there is a positive linear correlation exists between backscattering coefficient and AGB, the relationship was not strong. A negative linear relationship was observed between AGB and the land surface temperature. The amount of biomass estimated for dense and moderately dense vegetation for the HPNP using NDVI was $41.76 \mathrm{t} / \mathrm{ha}$, TIRS was $62.72 \mathrm{t} / \mathrm{ha}$, and HH polarized image was $38.9 \mathrm{t} / \mathrm{ha}$ add HV polarized image was $32.5 \mathrm{t} / \mathrm{ha}$. This study observed a weak negative relationship between land surface temperature from Landsat 8 TIRS with estimated AGB.

\section{ACKNOWLEDGEMENT}

The assistance provided by the research grant of the National Research Council (NRC), Sri Lanka (grant no:08 - 43) is greatly appreciated.

\section{REFERENCES}

Almeida, R., Shimabukuro, Y.E., Rosenqvist, A., and Sanchez, G.A. (2009). Using dualpolarized ALOS PALSAR data for detecting new fronts of deforestation in the Brazilian Amazonia. International Journal of Remote Sensing, 30, 3735 - 3743. 
Aranha, J.T., Viana, H.F. and Rodrigues, R., (2008). Vegetation classification by satellite image processing, A case study in North Portugal. International Conference and Exhibition on Bioenergy, April 6th - 9th 2008, Universidade do Minho, Guimarães, Portugal.

Bao Huy and Pham Tuan Anh, Vo Hung and Nguyen Thi Thanh Houng (2012). Report on estimation of $\mathrm{CO}_{2}$ sequestrated in evergreen broad leaf forest in Central Highland of Vietnam for reducing deforestation and forest degradation program. Tay Nguyen University, Dak Lac.

Baghdadi, N., Boyer, N., Todoroff, P., El Hajj, M., and Begue, A. (2009). Potential of SAR sensors TerraSAR-X, ASAR/ENVISAT and PALSAR/ALOS for monitoring sugarcane crops on Reunion Island. Remote Sensing of Environment, 113, 1724 - 1738.

Boyd, D.S., Foody, G.M. and Curran, P.J. (1999). The relationship between the biomass of Cameroonian tropical forests and radiation reflected in middle infrared wavelengths (3.0-5.0 mm). International Journal of Remote Sensing, 20, 1017 - 1023.

Brown, S. and Lugo A.E. (1982). The storage and production of organic matter in tropical forests and their role in the global carbon cycle. Biotropica, 14, 161 - 187.

Brown, S., Gillespie, A.J.R. and Lugo, A.E., (1989). Biomass estimation methods for tropical forests with applications to forest inventory data. Forest Science, 35, 881 - 902.

Chave, J., Andalo, C., Brown, S., Cairns, M.A., Chambers, J.Q., et al. (2005). Tree allometry and improved estimation of carbon stocks and balance in tropical forests. Oecologia, 145: 87 -99 .

Chokkalingam, U. and Vanniarachchy, S. A. (2011). Sri Lanka's REDD+ Potential: Myth or Reality. Forest Carbon Asia Country Profile Report No. 1: Sri Lanka.

Densheng, Lu., Mausel, P., Brondizio, E. and Moran, E. (2004). Relationship between forest stand parameters and Landsat TM spectral response in the Brazilian Amazon Basin, Forest Ecology and Management:157, 149-167.

DWC (2007). Biodiversity Baseline Survey: Horton Plains National Park. Department of Wildlife Conservation, Ministry of Environment and Natural Resources, Colombo. 40 p.

Eskil, M., Persson, U.M., Ostwald, M., Nissanka, S.P. (2012). REDD plus readiness implications for Sri Lanka in terms of reducing deforestation, Journal of Environmental Management, 100, 29 - 40.

Foody, G.M., Cutler, M.E., Mcmorrow, J., Pelz, D., Tangki, H., Boyd, D.S. and Douglas, I. (2001). Mapping the biomass of Bornean tropical rain forest from remotely sensed data. Global Ecology and Biogeography, 10, 379 - 387.

Foody, G.M. (2003). Remote sensing of tropical forest environments: towards the monitoring of environmental resources for sustainable development. International Journal of Remote Sensing, 24, 4035 - 4046.

Foster, A.J., Kakani, V.G. and Mosali, J.J. (2012). Predicting biomass yield in bioenergy crop production Systems using canopy NDVI. Proceedings of the 2012 Sun Grant National Conference. Vol 02. 
Huete, A.R., Jackson, R.D., \& Post, D.F. (1985). Spectral response of a plant canopy with different soil backgrounds. Remote Sensing of Environment, 17, 37 - 53.

Lu, D., Moran, E. and Batistella, M. (2003). Linear mixture model applied to Amazonian vegetation classification, Remote Sensing of Environment, 87, 456 - 469.

Lu, D. (2005). Aboveground biomass estimation using Landsat TM data in the Brazilian Amazon Basin. International Journal of Remote Sensing, 26, 2509 - 2525.

Lu D. (2006). The Potential and Challenge of Remote Sensing Based Biomass Estimation, International Journal of Remote Sensing 27(7), 1297 - 1328.

Namayanga, L.N. (2002). Estimating terrestrial carbon sequestered in above ground woody biomass from remotely sensed data. International Institute for Geo-information Science and Earth Observation, Netherlands: 10 - 12.

Nelson, R.F., Kimes, D.S., Salas, W.A. and Routhier, M. (2000). Secondary forest age and tropical forest biomass estimation using Thematic Mapper imagery. Bioscience, 50, 419 431.

Panda, B.C. (2005). Remote sensing principles and applications, Viva books Privet Limited, New Delhi. 100 - 148.

Roy, P.S., and Shirish A R. (1996). Biomass estimation using satellite remote sensing data an investigation on possible approached for natural forest. Journal of biosci., 21, 535 - 561.

Rozenstein, O., Zhihao, Q., Yevgeny, D., and Karnieli, A. (2014) Derivation of Land Surface Temperature for Landsat-8 TIRS Using a Split Window Algorithm. Sensors 2014, 14, 57685780.

Shimada, M., Isoguchi, O., Tadono, T. and Isono, K. (2009). PALSAR polarimetric calibration and geometric calibration. IEEE Transactions on Geoscience and Remote Sensing, 47, 12, 3915 - 3932.

Steininger, M.K. (2000). Satellite estimation of tropical secondary forest aboveground biomass data from Brazil and Bolivia. International Journal of Remote Sensing, 21, 1139 1157.

Thenkabail, P.S., Stucky, N., Griscom, B.W., Ashton, M.S., Diels, J., Van Der Meer, B. and Enclona, E. (2004). Biomass estimations and carbon stock calculations in the oil palm plantations of African derived savannas using IKONOS data. International Journal of Remote Sensing, 2, 5447 - 5472.

Tucker, C.J. (1979). Red and photographic infrared linear combinations for monitoring vegetation. Elsevier North Holland Inc. 8, 127 - 150.

Wan, Z., Wang, P. and Li, X. (2004). Using MODIS Land Surface Temperature and Normalized Difference Vegetation Index Products for Monitoring Drought in the Southern Great Plains, USA. International Journal of Remote Sensing 25, 61 - 72. 
Zanne, A.E., Lopez-Gonzalez, G., Coomes, D.A., Ilic, J., Jansen, S., Lewis, S.L., Miller, R.B., Swenson, N.G., Wiemann, M.C., Chave, J. (2009). Global wood density database. Dryad. Identifier: http://hdl.handle.net/10255/dryad.235. 